There is also a somewhat old-fashioned air about the material as if it was conceived before such vulgar objects as automated blood counters arrived on the scene. Blood counts are more often than not presented to the clinician as the output of automated counters, and the physician may have to consider how an abnormal MCH and/or MCV fits into the clinical picture. Unfortunately the clinician will not receive much help from this book. Alcoholism, an increasingly important cause of blood changes, is not mentioned nor is the common nutritional vitamin $B_{12}$-deficiency of Asian vegetarians. The diagnosis of polycythaemia rubra vera does not take into account arterial oxygen saturation, P50 values nor the relative merits of chlorambucil radiophosphorus or venesection and their relation to leukaemia. The differential diagnosis of iron deficiency omits the important anaemia of chronic disorders as in rheumatoid arthritis (but congenital transferrin deficiency is included).

Is the abnormal cell in glandular fever a mononuclear and not a lymphocyte and is 'fingers' the best way to record changes in the size of the spleen?

The book exceeds 460 pages and is approaching the middle division in length. One hopes the next edition of this deservedly successful book will rectify these and other omissions which indicate just a touch of middle-age spread.

\section{Treatment. A Handbook of Drug Therapy}

Edited by O. L. WAde, L. Beeley, V. W. M. Drury and P. A. Alesbury. Instalment 1. Kluwer Publishing, Brentford, Middlesex, 1979. First instalment, $£ 6.50$ with 2 binders at $£ 1.80$ each. Updating Service, annual subscription c. $£ 7.00$.

Those who are familiar with its 2 predecessors - 'Practice' and 'Laboratory' - in the series of loose-leaf manuals for general practitioners will need no explanation of the basic concept which this book follows. At present under review are the first 2 of the 5 instalments which will complete 'Treatment'; 2 binders will be needed to house the set. Ultimately, at approximately yearly intervals, replacement pages will be available where needed, so that each manual will be up-to-date. The manual is to be in 2 main sections, plus an appendix. The latter is to include a list of drug interactions, drug-induced diseases and drug prescribing in renal failure, pregnancy and lactation.

The first section is a list of drugs classified by their therapeutic action, together with their British proprietory names and approximate costings. It is impossible not to compare this part of the manual with the Monthly Index of Medical Specialities (MIMS) which every British GP gets once a month free of charge. Indeed, the editors of 'Treatment' acknowledge that that book is one of the 2 reference sources for the list of drugs they give. MIMS has the advantage of appearing monthly, not yearly, so that it is indeed up-to-date.

The second section is by far the most valuable. It is a description by symptoms of the diseases most commonly seen in general practice. The quality of the chapters varies considerably. A few are so terse and/or dogmatic that they tend to confuse more than they edify. Either the reader $\overrightarrow{\mathbb{D}}$ knows all - or practically all - that is written therein and will $\varrho$ not need the book, or he will need much more detail about $\subseteq$ when and how to prescribe a particular drug in general practice and what are likely to be the side effects.

One criticism of detail: why is it recommended that so 0 many drugs (for example, anti-rheumatics) should be taken $\frac{\bar{\sigma}}{\sigma}$ every $6 \mathrm{hr}-$ which is how I interpret q6h. Only a grossly $\frac{\bar{\omega}}{\bar{\omega}}$ obsessional patient is going to follow that sort of regime. $\frac{\mathrm{T}}{\overrightarrow{0}}$ Most patients are likely to say to themselves: 'Every six $\mathbb{D}$ hours means 6 a.m., noon, 6 p.m. and midnight'. As they are usually asleep at 6 a.m. and midnight they will only take $\omega$ their medication on the other 2 occasions! If by q6h the $\overrightarrow{0}$ authors mean 4 times a day (on rising, midday, late afternoon and before retiring) why not say so (qds)?

From the chapter list provided there does not appear to be any specific article on patient compliance, nor on poly- $\delta$ pharmacy, both important in general practice. Because the $\frac{O}{3}$ book is loose-leaf it is not too late to have them included. Indeed, because the book appears mainly to be directed at $\mathrm{Gr}$ the trainee GP, a chapter on how to write a prescription, as well as reference to the various drug regulations, would not $\$$ be amiss, nor would something about repeat prescriptions.

\section{X-Ray Anatomy}

By George Simon and W. J. Hamilton. Pp. 343, illustrated. Butterworths, London, Boston, 1978. $£ 25.00$.

'Good God, how do you expect to become a radiologist if $\bigcirc$ you don't know your anatomy?' Dr Simon's question will $\stackrel{\circ}{\circ}$ always be apt, and he has provided a book to help not only $\mathbb{D}$ the aspiring radiologist, but also physicians and surgeons.

In 343 pages, divided into 8 chapters and 2 appendices, the book 'describes and illustrates elementary and advanced $\vartheta$ radiological anatomy' concisely and comprehensibly, witho $\overline{\mathrm{B}}$ going into detailed relationships. Surface anatomy, develo ment, common anatomical variants and changes with position are dealt with in the text and the numerous clear illustrations.

The illustrations are of high quality but one or two arrows are misplaced and the captions of Fig 428 (a) and (b) have been switched.

In the first chapter there is a brief account of how X-rays are produced and recorded, but it does not have enough detail for the radiologist so is presumably directed at others.

The skeleton and thorax together take up more than half the book; this reflects the authors' interest. Less detail is given to the abdomen; for example the liver, gall-bladder, spleen and pancreas are dealt with in two-and-a-half pages. These are shown better by ultrasound and CT scanning and transverse section anatomy has not been included in this book.

On the whole, this is a well written book and is recommended to trainee radiologists. They will have to supple- $\delta$ ment it with more detail in some sections. More senior radiologists will find it useful in refreshing the memory, especially the accounts of development. Surgeons will need much more detail, but should find the illustrations helpful. 